\title{
Comparative Study of Efficacy and Safety of Atorvastatin plus Fenofibrate versus Atorvastatin plus Saroglitazar in Patients of Type 2 Diabetes Mellitus with Dyslipidemia
}

\section{Dr. Mohd Faheem Mubeen}

Associate Professor, Department of Pharmacology, Maheshwara Medical College and Hospital, Chitkul (V), Near Isnapur X Roads, Patancheruvu, Telangana 502307, India

DOI: $\underline{10.36348 / \mathrm{sb} .2020 . \mathrm{v} 06 \mathrm{i} 12.001}$

| Received: 09.12.2020 | Accepted: 19.12.2020 | Published: 24.12.2020

*Corresponding author: Dr. Mohd Faheem Mubeen

\section{Abstract}

Introduction: In India, the number of people with diabetes is increasing day-by-day. Due to a sole "Asian Indian Phenotype," Indians develop diabetes an era earlier and have an earlier onset of complications. Dyslipidemia with diabetes commonly manifests as raised low-density lipoprotein cholesterol (LDL-C), decreased high-density lipoprotein cholesterol (HDL-C) levels, or elevated triglyceride (TG) levels. It is also reported that plaques are more vulnerable to rupture among patients with diabetes. Material and Methods: The present study was Prospective, open label, comparative, randomized, parallel group, single center study. Comparison of two active treatment groups over a period of 24 weeks. Total 184 patients of either sex in the age group of 30-60 years with diabetes and dyslipidemia according to NCEP. The effect of Atorvastatin plus Fenofibrate and Atorvastatin plus Saroglitazar were observed on various parameters i.e. Total Cholesterol, Serum Triglyceride (TG), Serum Very low-density lipoproteins (VLDL), Serum Lowdensity lipoproteins (LDL), Serum High-density lipoproteins (HDL). Results: In Atorvastatin plus Fenofibrate group the mean change of Total Cholesterol from baseline to 24 weeks was $304.80 \pm 49.22$ to $256.20 \pm 49.12$; on the other hand, in Atorvastatin plus Saroglitazar group from baseline to 24 weeks was $312.57 \pm 53.81$ to $226.16 \pm 46.75$. Whereas, Serum TG from $247.71 \pm 56.51$ to $211.86 \pm 82.52$ in Fenofibrate group; in Saroglitazar group from 244.05 \pm 66.97 to $174.91 \pm 57.61$. Whereas, Saroglitazar group improve HDL from $38.43 \pm 5.82$ to $51.07 \pm 6.86$. Conclusions: Though Atorvastatin plus Fenofibrate and Atorvastatin plus Saroglitazar were effective in improving dyslipidemic indices yet Saroglitazar statistically highly significant than Fenofibrate group in improving dyslipidemia. Saroglitazar showed better results in decreasing Total Cholesterol, TG, LDL, VLDL and improving HDL as compared with Fenofibrate.

Keywords: Dyslipidemia Type 2 Diabetes Mellitus, Atorvastatin, Fenofibrate, Saroglitazar.

Copyright () 2020 The Author(s): This is an open-access article distributed under the terms of the Creative Commons Attribution 4.0 International License (CC BY-NC 4.0) which permits unrestricted use, distribution, and reproduction in any medium for non-commercial use provided the original author and source are credited.

\section{INTRODUCTION}

Diabetes mellitus is one of the most common chronic diseases globally and continues to increase in numbers. It is among the top five causes of mortality. The global prevalence of diabetes among adults is estimated to be $6.4 \%$, affecting 285 million people, in 2010, and is expected to increase to $7.7 \%$, affecting 439 million people by 2030. Between 2010 and 2030, it is estimated that there will be a $69 \%$ and $20 \%$ increase in number of adults with diabetes in developing countries and developed countries, respectively. Diabetes has evolved into an epidemic in India. The estimated number of patients with diabetes in India was 62.4 million in 2011 which is projected to rise to a staggering 101.2 million by 2030. Overall crude prevalence of self-reported diabetes in India 14.6\% [1$3]$.

Statins are inhibitors of 3-hydroxy-3methylglutaryl-coenzyme A (HMG-CoA)-reductase, a key enzyme involved in the cholesterol biosynthesis. Statins are successful in the management of dyslipidemia. Considerable number of hyperlipidemia patients on statin therapy has residual cardiovascular risk [4-13]. Therefore, combination of fenofibrate with a statin was suggested -to be a useful therapeutic option to improve lipid profile and to reduce cardiovascular risk. Moreover, combined treatment with statins and fibrates is additional efficient in controlling atherogenic dyslipidemia than the management of any drug alone [14]. 
Atorvastatin is a potent inhibitor of hydroxymethylglutaryl-CoA reductase, which decreases LDL cholesterol in plasma by regulating LDL receptor activity [15]. It has been shown that atorvastatin significantly reduced circulating levels of all major LDL subspecies: light, intermediate, and dense [16]; the latter is believed to be responsible for the TG-lowering effect of atorvastatin and has profound effects at higher doses [17].

Fenofibrate activates peroxisome proliferatoractivated receptors [18], which stimulate an increase in LP lipase action and a decrease in cholesterol ester transport protein action. These result in $\mathrm{TG}$ level reduction, redistribution of LDL particle size, and an HDL cholesterol increase. The significant reduction of TG, and increase in HDL cholesterol, seen in this study with atorvastatin and fenofibrate combination is indicative of a beneficial increase in LDL particle size [19].

Dual PPAR- $\alpha / \gamma$ agonist has been studied for decades now for the treatment of diabetes and dyslipidemia as these metabolic disorders coexist in a majority of the patients and pose a significant CVD risk. A study by Boden $G$ et al. on benefits of combination of PPAR- $\alpha$ agonist and PPAR- $\gamma$ agonist has shown the combination therapy prevented fluid retention and had significantly better efficacy in lowering FFA, TG and HbAlc compared to monotherapy of each in T2DM. Saroglitazar is the first indigenously developed new chemical entity which is also the first glitazar to be approved for the management of Diabetic dyslipidemia [20]. Although diabetes and dyslipidemia commonly coexist in India, there is a lack of evidence on whether dyslipidemia is adequately managed or not [21]. At present, there is lack of country wide data for meaningful analysis. Therefore, there existed a need to understand the effect of combination of statin and glitazars on pattern of dyslipidemia and accurately assess the control of lipids in this population in a real-world setting. The primary objective of our study was to assess the control of dyslipidemia in the Indian patients with diabetes treated with lipid lowering drugs (LLDs). Hence this study was planned to compare efficacy and safety of atorvastatin plus fenofibrate versus atorvastatin plus saroglitazar in patients of type 2 diabetes mellitus with dyslipidemia.

\section{METHODOLOGY}

\section{Inclusion Criteria}

- Patients willing to participate in the study and following protocol.

- $\quad$ Age group of 30-60 years.

- Newly diagnosed diabetic patients with dyslipidemia.

- $\quad$ Deranged lipid range (As per NCEP)

NCEP Guidelines of deranged lipid profile

\begin{tabular}{|l|l|l|l|l|}
\hline CV Risk & Total Cholesterol $(\mathbf{m g} / \mathbf{d l})$ & Triglycerides $(\mathbf{m g} / \mathbf{d l})$ & HDL $(\mathbf{m g} / \mathbf{d l})$ & LDL $(\mathbf{m g} / \mathbf{d l})$ \\
\hline Higher & $>240 \mathrm{mg} / \mathrm{dl}$ & $>200 \mathrm{mg} / \mathrm{dl}$ & $<40 \mathrm{mg} / \mathrm{dl}$ & $>160 \mathrm{mg} / \mathrm{dl}$ \\
\hline Borderline High & $200-239 \mathrm{mg} / \mathrm{dl}$ & $150-199 \mathrm{mg} / \mathrm{dl}$ & $40-50 \mathrm{mg} / \mathrm{dl}$ & $130-159 \mathrm{mg} / \mathrm{dl}$ \\
\hline Desirable & $<200 \mathrm{mg} / \mathrm{dl}$ & $<150 \mathrm{mg} / \mathrm{dl}$ & $60 \mathrm{mg} / \mathrm{dl}$ & $100-129 \mathrm{mg} / \mathrm{dl}$ \\
\hline
\end{tabular}

\section{Exclusion Criteria}

- The patients with

a. Secondary hypertension.

b. Bronchial asthma.

c. Chronic obstructive pulmonary diseases.

d. Any other respiratory diseases.

e. Any cardiovascular disorders / Any Hepatic or renal diseases.

- Pregnant and lactating women.

- Known allergic to drugs.

- Patient concurrently taking other medication which is known to affect the blood pressure and lipid parameters.

- Smoker, alcoholic and tobacco chewer.

\section{STUDY DESIGN}

- Present study is randomized open label parallel single center prospective clinical study of 6 months' duration.

- Present study was carried out at Maheshwara medical college and hospital.

- Study was conducted after obtaining permission from institutional ethics committee.
- After fulfilment of inclusion criteria and informed written consent was obtained from patients, after that study was started.

- Patient was divided into two arms

- $1^{\text {st }}$ arm patients were received Tab. Atorvastatin $10 \mathrm{mg}+$ Tab. Fenofibrate $145 \mathrm{mg}$

- $2^{\text {nd }}$ arm patients were received Tab. Atorvastatin 10mg + Tab. Saroglitazar 4g

\section{ASSESSMENT AT BASELINE VISIT}

- General physical examination

- Compliance of the patients

- Laboratory investigations:

- Serum Total Cholesterol.

- Serum Triglyceride.

- Serum Very low-density lipoproteins (VLDL).

- Serum Low-density lipoproteins (LDL).

- Serum High-density lipoproteins (HDL).

\section{ASSESSMENT AT 12 WEEKS VISIT}

- General physical examination

- Compliance of the patients 
- $\quad$ ADR reporting

\section{ASSESSMENT AT 24 WEEKS VISIT}

1. General physical examination

2. Compliance of the patients

3. Laboratory investigations:

- Serum total cholesterol.

- Serum triglyceride

- Serum very low-density lipoproteins (VLDL).

- Serum low-density lipoproteins (LDL).

- Serum high-density lipoproteins (HDL).

4. ADR reporting

\section{WITHDRAWAL AND DROP OUTS:}

Patients were advised in the informed consent that they have the right to withdraw from the study at any time without prejudice. Investigator was supposed to record the appropriate reason for discontinuation of the patient from the study. Typically, patient would have discontinued from the study for the following reasons:

1. At the request of the patient.

2. If the patient was subsequently found to have any of the listed exclusion criteria.

3. If the investigator considered that the patient's health will be compromised due to concomitant illness that has developed after entering the study.

4. Uncooperative patient after inclusion.

5. On the emergence of serious adverse event or an unacceptable laboratory result which according to the investigator required discontinuation.

6. Clinically significant violation of protocol which could impact the study outcome.

7. The patient did not turn for the follow up visit (s) following administration of the drug.

Patient withdrawn due to an adverse event (AE) were supposed to be followed until the adverse event was abated, or until a stable situation had been reached. All tests/examinations scheduled at study completion were supposed to be performed at premature termination/dropout. Drop outs were supposed to be replaced. All premature discontinuations, reasons and their causes were documented.

\section{STATISTICAL ANALYSIS}

- Data was compiled in MS Excel sheet

- Results was analysed using student "t-test."

- By using SPSS 21 (statistical package for social science) software data is analysed

- $\quad \mathrm{P}<0.05$ considered as statistically significant
- Considering the prevalence rate of total diabetic patients in India $14.6 \%$, my sample size came to 184

Sample size $=Z^{2} p(1-p) / d^{2}$

\section{COMPLIANCE WITH GOOD CLINICAL PRACTICE AND ETHICS CONSIDERATIONS}

This study was conducted in compliance with the protocol; the Institutional Ethics Research Committee (IERC), informed consent regulations and ICH/GCP Guidelines. Before initiating the study, written approval had been taken from IERC.

\section{RESULTS}

The present study was carried out in collaboration with the Department of Medicine, Maheshwara Medical College. A total 190 patients were enrolled and 6 patients were withdrawing from study due to their personal reasons and not attending the follow up visits and remaining 184 were randomly divided into two groups of 92 each.

\section{GROUP I: Atorvastatin (10mg) plus Fenofibrate (145mg)}

2. GROUP II: Atorvastatin (10mg) plus Saroglitazar (2mg)

Table-1: Distribution of patients according to AgeGroup

\begin{tabular}{|c|c|c|c|c|}
\hline \multirow[t]{2}{*}{ Age in years } & \multicolumn{2}{|c|}{ Group I } & \multicolumn{2}{|c|}{ Group II } \\
\hline & No & $\%$ & No & $\%$ \\
\hline $30-40$ & 27 & $29.3 \%$ & 28 & $30.4 \%$ \\
\hline $40-50$ & 36 & $39.1 \%$ & 38 & $41.3 \%$ \\
\hline $50-60$ & 29 & $31.6 \%$ & 26 & $28.3 \%$ \\
\hline Total & 92 & $100 \%$ & 92 & $100 \%$ \\
\hline Mean \pm SD & \multicolumn{2}{|c|}{$44.30 \pm 8.70$} & \multicolumn{2}{|c|}{$45.78 \pm 8.68$} \\
\hline
\end{tabular}

Table-1 shows the age distribution of the subjects in 2 groups under study. Two groups consisted of 92 subjects each.

Table-2: Distribution of patients according to Gender

\begin{tabular}{|l|l|l|l|l|}
\hline \multirow{2}{*}{ Gender } & \multicolumn{2}{|l|}{ Group I } & \multicolumn{2}{l|}{ Group II } \\
\cline { 2 - 5 } & No & $\%$ & No & \% \\
\hline Male & $\mathbf{4 0}$ & $\mathbf{4 3 . 5 \%}$ & $\mathbf{3 9}$ & $\mathbf{4 2 . 4 \%}$ \\
\hline Female & $\mathbf{5 2}$ & $\mathbf{5 6 . 5 \%}$ & $\mathbf{5 3}$ & $\mathbf{5 7 . 6 \%}$ \\
\hline Total & $\mathbf{9 2}$ & $\mathbf{1 0 0 \%}$ & $\mathbf{9 2}$ & $\mathbf{1 0 0 \%}$ \\
\hline
\end{tabular}

Table-2 shows the sex distribution of the subjects in 2 groups under study. Two groups consisted of 92 subjects each. Group I consisted of 40 male and 52 female patients. Male patients in Group II were 39 and female 53 . 
Faheem Mubeen., Sch Bull, Dec, 2020; 6(12): 247-256

Table-3: Comparison of Mean Total Cholesterol in both Groups at baseline \& after 24 wks of treatment by unpaired "t" test

\begin{tabular}{|l|l|l|l|l|}
\hline & Groups & Mean \pm SD & t-value & P-value \\
\hline \multirow{2}{*}{ Baseline } & Group I & $304.80 \pm 49.22$ & 1.02 & $\mathrm{P}=0.338$ \\
& Group II & $312.57 \pm 53.81$ & & $\mathrm{NS}$ \\
\hline After 24 weeks & Group I & $256.20 \pm 49.12$ & 4.25 & $\mathrm{P}<0.0001$ \\
& Group II & $226.16 \pm 46.75$ & & $\mathrm{~S}$ \\
\hline
\end{tabular}

$\mathrm{P}$ value $<0.05$ is significant \& $\mathrm{P}$ value $>0.05$ is not significant

Both the groups consisted of 92 subjects each. Before treatment with Group I the total Baseline cholesterol level was $304.8 \pm 49.2 \mathrm{mg} / \mathrm{dl}$ and after 24 weeks' treatment cholesterol level was 256.2 \pm 49.1 $\mathrm{mg} / \mathrm{dl}$. In Group II baseline total cholesterol level was
$312.6 \pm 53.8 \mathrm{mg} / \mathrm{dl}$ and after 24 weeks was $226.2 \pm 46.8$. While comparing between Group I and Group II, in Group I total cholesterol was highly significant reduced than Group II by using unpaired t-test $(\mathrm{p}<0.0001)$.

Table-4: Comparison of Mean Differences of Total Cholesterol at baseline \& After 24 weeks in Groups analyzed by paired " $t$ "test

\begin{tabular}{|l|l|l|l|}
\hline TC & Mean Difference & t-value & P-value \\
\hline Baseline Vs After 24 weeks in Group I & 48.59 & 6.36 & $\begin{array}{l}\mathrm{P}<0.0001 \\
\mathrm{~S}\end{array}$ \\
\hline Baseline Vs After 24 weeks in Group II & 86.41 & 12.40 & $\begin{array}{l}\mathrm{P}<0.0001 \\
\mathrm{~S}\end{array}$ \\
\hline
\end{tabular}

$\mathrm{P}$ value $<0.05$ is significant $\& \mathrm{P}$ value $>0.05$ is not significant

Both the groups consisted of 92 subjects each. Before treatment with Group I the total cholesterol level mean difference from Baseline to 48.59 after 24 months $\mathrm{mg} / \mathrm{dl}$ and in Group II $86.41 \mathrm{mg} / \mathrm{dl}$. While comparing between Group I and Group II, in Group I total cholesterol was highly significant reduced than Group II by using paired $\mathrm{t}$-test $(\mathrm{p}<0.0001)$.

Table-5: Comparison of Mean Total Triglycerides in both Groups at baseline \& after 24 wks of treatment by unpaired "t" test

\begin{tabular}{|l|l|l|l|l|}
\hline & Groups & Mean \pm SD & t-value & P-value \\
\hline \multirow{2}{*}{ Baseline } & Group I & $247.71 \pm 56.51$ & 0.401 & $\mathrm{P}=0.668$ \\
\cline { 2 - 3 } & Group II & $244.05 \pm 66.97$ & & $\mathrm{NS}$ \\
\hline \multirow{2}{*}{ After 24 weeks } & Group I & $211.86 \pm 82.52$ & 3.52 & $\mathrm{P}=0.001$ \\
\cline { 2 - 3 } & Group II & $\mathbf{1 7 4 . 9 1 \pm 5 7 . 6 1}$ & & $\mathrm{S}$ \\
\hline
\end{tabular}

$\mathrm{P}$ value $<0.05$ is significant \& $\mathrm{P}$ value $>0.05$ is not significant

Both the groups consisted of 92 subjects each. Before treatment with Group I the Baseline Serum Triglycerides level was $247.7 \pm 56.5 \mathrm{mg} / \mathrm{dl}$ and after 24 weeks treatment Serum Triglycerides was $211.86 \pm 82.52 \mathrm{mg} / \mathrm{dl}$. In Group II baseline Serum
Triglycerides level was $244.05 \pm 66.97 \mathrm{mg} / \mathrm{dl}$ and after 24 weeks was $174.9 \pm 57.61$. While comparing between Group I and Group II, in Group II Serum Triglycerides was highly significant reduced than Group I by using unpaired t-test $(\mathrm{p}<0.0001)$.

Table-6: Comparison of Mean Differences of Serum Triglycerides at baseline \& After 24 weeks in Groups analyzed by paired "t "test

\begin{tabular}{|l|l|l|l|}
\hline TG & Mean Difference & t-value & P-value \\
\hline Baseline Vs After 24 week in Group I & 35.84 & 4.61 & $\begin{array}{l}\text { P<0.0001 } \\
\text { S }\end{array}$ \\
\hline Baseline Vs After 24 week in Group II & 69.14 & 9.08 & $\begin{array}{l}\mathrm{P}<0.0001 \\
\mathrm{~S}\end{array}$ \\
\hline
\end{tabular}

$\mathrm{P}$ value $<0.05$ is significant $\& \mathrm{P}$ value $>0.05$ is not significant.

Both the groups consisted of 92 subjects each. Before treatment with Group I the Serum Triglycerides level mean difference from Baseline to after 24 months $35.85 \mathrm{mg} / \mathrm{dl}$ and in Group II $69.14 \mathrm{mg} / \mathrm{dl}$. While comparing between Group I and Group II, in Group II was highly significant reduced than Group I by using paired t-test $(\mathrm{p}<0.0001)$. 
Faheem Mubeen., Sch Bull, Dec, 2020; 6(12): 247-256

Table-7: Comparison of Mean HDL in both Groups at baseline \& after 24 wks of treatment by unpaired " $t$ " test

\begin{tabular}{|l|l|l|l|l|}
\hline \multirow{2}{*}{ Baseline } & Groups & Mean \pm SD & t-value & P-value \\
& Group I & $39.34 \pm 5.76$ & 1.07 & $\mathrm{P}=0.287$ \\
\cline { 2 - 3 } & Group II & $38.43 \pm 5.82$ & & $\mathrm{NS}$ \\
\hline \multirow{2}{*}{ After 24 weeks } & Group I & $44.38 \pm 5.65$ & 7.21 & $\mathrm{P}<0.0001$ \\
\cline { 2 - 3 } & Group II & $51.07 \pm 6.86$ & & $\mathrm{~S}$ \\
\hline
\end{tabular}

$\mathrm{P}$ value $<0.05$ is significant $\& \mathrm{P}$ value $>0.05$ is not significant

Both the groups consisted of 92 subjects each. Before treatment with Group I the Baseline HDL Cholesterol level was $39.34 \pm 5.76 \mathrm{mg} / \mathrm{dl}$ and after 24 weeks treatment HDL Cholesterol level 44.38 \pm 5.65 $\mathrm{mg} / \mathrm{dl}$. In Group II baseline HDL Cholesterol level was
$38.43 \pm 5.82 \mathrm{mg} / \mathrm{dl}$ and after 24 weeks $51.07 \pm 6.86$. While comparing between Group I and Group II, in Group II HDL Cholesterol was highly significant increased than Group I by using unpaired t-test $(\mathrm{p}<0.0001)$.

Table-8: Comparison of Mean Differences of HDL-CH at baseline \& After 24 weeks in Groups analyzed by paired

\begin{tabular}{|l|l|l|l|}
\hline HDL & Mean Difference & t-value & P-value \\
\hline Baseline Vs After 24 week in Group I & 5.04 & 6.58 & $\begin{array}{l}\mathrm{P}<0.0001 \\
\mathrm{~S}\end{array}$ \\
\hline Baseline Vs After 24 week in Group II & 12.64 & 13.21 & $\begin{array}{l}\mathrm{P}<0.0001 \\
\mathrm{~S}\end{array}$ \\
\hline
\end{tabular}

$\mathrm{P}$ value $<0.05$ is significant $\& \mathrm{P}$ value $>0.05$ is not significant

Both the groups consisted of 92 subjects each. Before treatment with Group I the HDL Cholesterol level mean difference from Baseline to after 24 months $5.04 \mathrm{mg} / \mathrm{dl}$ and in Group II $12.64 \mathrm{mg} / \mathrm{dl}$. While comparing between Group I and Group II, in Group II HDL Cholesterol was highly significant increased than Group I by using paired t-test $(\mathrm{p}<0.0001)$.

Table-9: Comparison of Mean LDL-CH in both Groups at baseline \& after 24 wks of treatment by unpaired "t" test

\begin{tabular}{|l|l|l|l|l|}
\hline LDL & Groups & Mean \pm SD & t-value & P-value \\
\hline \multirow{2}{*}{ Baseline } & Group I & $217.56 \pm 51.45$ & 0.769 & $\begin{array}{l}\mathrm{P}=0.443 \\
\text { NS }\end{array}$ \\
\cline { 2 - 3 } & Group II & $223.68 \pm 56.54$ & & $\begin{array}{l}\mathrm{P}<0.0001 \\
\text { After 24 weeks }\end{array}$ \\
\cline { 2 - 3 } & Group I & $170.14 \pm 53.40$ & 4.05 & $\mathrm{~S}$ \\
\cline { 2 - 3 } & Group II & $139.39 \pm 49.56$ & & \\
\hline
\end{tabular}

$\mathrm{P}$ value $<0.05$ is significant $\& \mathrm{P}$ value $>0.05$ is not significant

Both the groups consisted of 92 subjects each. Before treatment with Group I the Baseline LDL cholesterol level was $217.56 \pm 51.45 \mathrm{mg} / \mathrm{dl}$ and after 24 weeks treatment LDL cholesterol was 170.14 \pm 53.40 $\mathrm{mg} / \mathrm{dl}$. In Group II baseline LDL cholesterol level was
$223.68 \pm 56.54 \mathrm{mg} / \mathrm{dl}$ and after 24 weeks was 139.39 \pm 49.56 . While comparing between Group I and Group II, in Group I LDL cholesterol was highly significant reduced than Group II by using unpaired ttest $(\mathrm{p}<0.0001)$.

Table-10: Comparison of Mean Differences of LDL-CH at baseline \& After 24 weeks in Groups analyzed by paired "t "test

\begin{tabular}{|l|l|l|l|}
\hline LDL & Mean Difference & t-value & P-value \\
\hline Baseline Vs After 24 week in Group I & 47.41 & 5.77 & $\begin{array}{l}\mathrm{P}<0.0001 \\
\mathrm{~S}\end{array}$ \\
\hline Baseline Vs After 24 week in Group II & 84.29 & 11.79 & $\begin{array}{l}\mathrm{P}<0.0001 \\
\mathrm{~S}\end{array}$ \\
\hline
\end{tabular}

$\mathrm{P}$ value $<0.05$ is significant $\& \mathrm{P}$ value $>0.05$ is not significant

Both the groups consisted of 92 subjects each. Before treatment with Group I the LDL cholesterol level mean difference from Baseline to after 24 months $47.41 \mathrm{mg} / \mathrm{dl}$ and in Group II $84.29 \mathrm{mg} / \mathrm{dl}$. While comparing between Group I and Group II, in Group I LDL cholesterol was highly significant reduced than Group II by using paired t-test $(\mathrm{p}<0.0001)$. 
Faheem Mubeen., Sch Bull, Dec, 2020; 6(12): 247-256

Table-11: Comparison of Mean VLDL-CH in both Groups at baseline \& after 24 wks of treatment by unpaired "t" test

\begin{tabular}{|l|l|l|l|l|}
\hline VLDL & Groups & Mean \pm SD & t-value & P-value \\
\hline \multirow{2}{*}{ Baseline } & Group I & $49.54 \pm 11.30$ & 0.401 & $\mathrm{P}=0.689$ \\
\cline { 2 - 3 } & Group II & $48.81 \pm 13.39$ & & $\mathrm{NS}$ \\
\hline After 24 weeks & Group I & $42.37 \pm 16.50$ & 3.52 & $\mathrm{P}=0.001$ \\
\cline { 2 - 3 } & Group II & $34.98 \pm 11.52$ & & $\mathrm{~S}$ \\
\hline
\end{tabular}

$\mathrm{P}$ value $<0.05$ is significant \& $\mathrm{P}$ value $>0.05$ is not significant

Both the groups consisted of 92 subjects each. Before treatment with Group I the Baseline VLDL cholesterol level was $49.5 \pm 11.3 \mathrm{mg} / \mathrm{dl}$ and after 24 weeks treatment VLDL cholesterol was $42.3 \pm 16.5$ $\mathrm{mg} / \mathrm{dl}$. In Group II baseline VLDL cholesterol level was
$48.8 \pm 13.39 \mathrm{mg} / \mathrm{dl}$ and after 24 weeks $34.98 \pm 11.5 \mathrm{mg} / \mathrm{dl}$. While comparing between Group I and Group II, in Group I VLDL cholesterol was highly significant reduced than Group II by using unpaired t-test $(\mathrm{p}<0.0001)$.

Table-12: Comparison of Mean Differences of LDL-CH Cholesterol at baseline \& After 24 weeks in Groups analyzed by paired " $t$ "test

\begin{tabular}{|l|l|l|l|}
\hline V.L.D.L. & Mean Difference & t-value & P-value \\
\hline Baseline Vs After 24 weeks in Group I & 7.17 & 4.61 & $\begin{array}{l}\mathrm{P}<0.0001 \\
\text { S }\end{array}$ \\
\hline Baseline Vs After 24 weeks in Group II & 13.82 & 9.08 & $\begin{array}{l}\mathrm{P}<0.0001 \\
\mathrm{~S}\end{array}$ \\
\hline
\end{tabular}

$\mathrm{P}$ value $<0.05$ is significant $\& \mathrm{P}$ value $>0.05$ is not significant

Both the groups consisted of 92 subjects each. Before treatment with Group I the VLDL cholesterol level mean difference from Baseline to after 24 months $7.17 \mathrm{mg} / \mathrm{dl}$ and in Group II $13.83 \mathrm{mg} / \mathrm{dl}$. While comparing between Group I and Group II, in Group II VLDL cholesterol was highly significant reduced than Group I by using paired t-test $(\mathrm{p}<0.0001)$.

Table-13: Overview of the Total changes in Lipid parameters after the therapy

\begin{tabular}{|c|c|c|}
\hline $\begin{array}{ll}\text { LIPID } \\
(\mathrm{mgs} \%)\end{array}$ & $\begin{array}{ll}\text { Group I } & \text { (Baseline Vs After 24 } \\
\text { months) }\end{array}$ & $\begin{array}{ll}\text { Group II } & \text { (Baseline Vs After } \\
24 \text { months) } & \\
\end{array}$ \\
\hline Total Cholesterol & $\downarrow 48.59$ & $\downarrow 86.41$ \\
\hline Serum Triglycerides & $\downarrow 35.84$ & 69.14 \\
\hline H.D.L. Cholesterol & $\downarrow 5.04$ & $\downarrow \quad 12.64$ \\
\hline L.D.L. Cholesterol & $\downarrow 47.41$ & $\downarrow \quad 84.29$ \\
\hline V.L.D.L. Cholesterol & $\downarrow \quad 7.17$ & $\downarrow 13.83$ \\
\hline
\end{tabular}

\section{DISCUSSION}

Diabetes Mellitus (DM) is a metabolic disorder of multiple etiology characterized by chronic hyperglycemia with disturbances of carbohydrate, fat and protein metabolism resulting from defects in insulin secretion, insulin action, or both. The direct and indirect effects on the human vascular tree are the major source of morbidity and mortality in both type 1 and type 2 diabetes [22]. Generally, the injurious effects of hyperglycemia are separated into macro vascular complications (coronary artery disease, peripheral arterial disease, and stroke) and microvascular complications (diabetic nephropathy, neuropathy, and retinopathy). It is important to understand the relationship between diabetes and vascular disease because the prevalence of diabetes continues to increase in the India, and the need for the primary and secondary prevention of these complications is also expanding [23].
The global prevalence of diabetes among adults is estimated to be $6.4 \%$, affecting 285 million people, in 2010, and is expected to increase to $7.7 \%$, affecting 439 million people by 2030 . Between 2010 and 2030 , it is estimated that there will be a $69 \%$ and $20 \%$ increase in number of adults with diabetes in developing countries and developed countries, respectively. Diabetes has evolved into an epidemic in India. The estimated number of patients with diabetes in India was 62.4 million in 2011 which is projected to rise to a staggering 101.2 million by 2030 . Overall crude prevalence of self-reported diabetes in India $14.6 \%$ [24].

Prevalence of dyslipidemia among diabetic patients at baseline was $85.5 \%$ among males and $97.8 \%$ among females. Among the males with dyslipidemia the proportion of patients with mixed dyslipidemia, combined dyslipidemia and single parameter dyslipidemia were $14.1 \%, 44.9 \%$ and $41 \%$, respectively. Figures for the same among female 
patients stood at $24.6 \%, 47.8 \%$ and $27.7 \%$, respectively. Combined dyslipidemia with high LDL and low HDL was the most common pattern among males and females both, contributing to $22.7 \%$ and $33 \%$ patients of diabetic dyslipidemia, respectively. Second most common pattern among males was isolated high LDL, contributing to $21.3 \%$ of males with dyslipidemia. While among females isolated low HDL emerged as the second most common pattern affecting $13.4 \%$ dyslipidemic females. Majority of Indian type 2 diabetic patients are dyslipidemic at baseline. The most common pattern of dyslipidemia is high LDL and low HDL among both males and females. The most prevalent problem among males is high LDL while among females low HDL emerged as a bigger threat [25].

The central pathological mechanism in macro vascular disease is the process of atherosclerosis, which leads to narrowing of arterial walls throughout the body. Atherosclerosis is thought to result from chronic inflammation and injury to the arterial wall in the peripheral or coronary vascular system [26]. In response to endothelial injury and inflammation, oxidized lipids from LDL particles accumulate in the endothelial wall of arteries. Monocytes then infiltrate the arterial wall and differentiate into macrophages, which accumulate oxidized lipids to form foam cells. Once formed, foam cells stimulate macrophage proliferation and attraction of T-lymphocytes. T-lymphocytes, in turn, induce smooth muscle proliferation in the arterial walls and collagen accumulation. The net result of the process is the formation of a lipid-rich atherosclerotic lesion with a fibrous cap. Rupture of this lesion leads to acute vascular infarction. Both macrovascular and microvascular complications cause significant morbidity and mortality among diabetic subjects [27].

The Chennai Urban Population Study (CUPS) and CURES provided valuable data from India on the complications related to diabetes. The prevalence of coronary artery disease was 21.4 per cent among diabetic subjects compared to 9.1 per cent in subjects with normal glucose tolerance. The prevalence of CAD (coronary artery diseases) in IGT subjects were 14.9 per cent in the same study [28].

Diabetes mellitus induces a state of dyslipidemia with abnormality in all classes of lipids. The importance of lipid disorders in diabetes is due to an increased risk of accelerated atherosclerosis in patients with diabetes [29].

Type 2 diabetes mellitus is emerging as a silent killer in the Indian population as compared to the west where there is awareness of the disease and its complications. There is considerable evidence that the lipid lowering therapy with statins reduces the macrovascular complications as well as microvascular complications in the patients of type 2 diabetes mellitus which is a very important aspect to be addressed in the primary and secondary prevention of complications [30].

In our present study, the patients included in the study were Type 2 Diabetes Mellitus patients with dyslipidemia. The criteria for evaluation were lipid profile parameters i.e. Serum Cholesterol, Serum triglycerides, H.D.L., L.D.L., and V.L.D.L. respectively.

In our present study, we found that Group I: Atorvastatin plus Fenofibrate and Group II: Atorvastatin plus Saroglitazar both the groups had significantly decreased the levels of Serum Cholesterol, Triglycerides, L.D.L. and V.L.D.L. and also significantly increased HDL level after 24 weeks of therapy. But when we compare between these two groups Group I and Group II mean reduction done in all the parameters (Total Cholesterol, Serum Triglycerides, LDL \& VLDL) is more in Group II. The increase in the levels of Serum HDL with Group II also more in comparison with Group I.

The difference in the parameters studied was highly significant $(\mathrm{P}<0.001)$. These results are comparable to the studies conducted by Gleuk et al., which was conducted at The Cholesterol Centre, Jewish Hospital, Cincinati, USA [31]. These results correlate with the studies conducted by Goudevenos et al., for the efficacy of Atorvastatin and Simvastatin in dyslipidemia respectively [32].

In comparison of mean reduction of Total cholesterol in Group II (86.41 mg/dl, t value 12.40) when compared with mean reduction of serum cholesterol of Group I (48.59 mg/dl \& t value 6.36) has revealed that reduction in Total cholesterol levels of Group II was statistically highly significant when compared with the Group I as the mean reduction values are more in Group II $(\mathrm{p}<0.0001)$ [33].

In comparison of mean reduction of Serum Triglycerides in Group II (69.14 mg/dl \& t value 9.08) when compared with mean reduction of Serum Triglycerides of Group I (35.84 mg/dl \& t value 4.61) has revealed that reduction in Serum Triglycerides levels of Group II was statistically highly significant when compared with the Group I as the mean reduction values are more in Group II $(\mathrm{p}<0.0001)$. There are comparable studies done by Bullano et al., which concluded that Saroglitazar group was more effective than Fenofibrate group in decreasing the Triglycerides levels significantly [34].

In comparison of mean difference of increase in H.D.L. levels in Group II $(12.64 \mathrm{mg} / \mathrm{dl} \& \mathrm{t}$ value 13.21) when compared with mean difference of increase in H.D.L. levels of Group I (5.04 mg/dl \& t value 6.58) 
has revealed that reduction in H.D.L. levels of Group II was statistically highly significant when compared with the Group I as the mean difference of increase in HDL levels are more in Group II $(p<0.0001)$. These results of our study matches with the study done by Hunning et al., which concluded that Atorvastatin plus Saroglitazar produced more increase in the H.D.L. levels [35].

In comparison of mean reduction of L.D.L. cholesterol in Group II (84.29 mg/dl, t value 11.79) when compared with mean reduction of serum cholesterol of Group I group (47.41 mg/dl \& $\mathrm{t}$ value 5.77) has revealed that reduction in L.D.L. cholesterol levels of Group II was statistically highly significant when compared with the Group I as the mean reduction values are more in Group II $(\mathrm{p}<0.0001)$. There was comparable to the studies done by Disha et al., which concluded that Atorvastatin and Fenofibrate was more effective than both Atorvastatin plus Saroglitazar in decreasing the L.D.L. levels significantly [36].

In comparison of mean reduction of V.L.D.L. cholesterol in Group II (13.82 mg/dl, t value 9.08) when compared with mean reduction of V.L.D.L. cholesterol of Group I ( $7.17 \mathrm{mg} / \mathrm{dl} \& \mathrm{t}$ value 4.61$)$ has revealed that reduction in V.L.D.L. cholesterol levels of Group II was statistically highly significant when compared with the Group I as the mean reduction values are more in Group II $(p<0.0001)$. There was comparable to the studies done by Disha et al., which concluded that Atorvastatin and Fenofibrate was more effective than both Atorvastatin plus Saroglitazar in decreasing the L.D.L. levels significantly [37].

\section{CONCLUSION}

In summary, after 24 weeks of treatment with Atorvastatin $10 \mathrm{mg}$ plus Saroglitazar $2 \mathrm{mg}$ OD mean reduction caused in Total Cholesterol, Serum TG, LDL$\mathrm{CH}$, and VLDL- $\mathrm{CH}$ values in group II is more while compared with Group I comprising of Atorvastatin $10 \mathrm{mg}$ plus Fenofibrate $145 \mathrm{mg}$ OD. Whereas, Atorvastatin $10 \mathrm{mg}$ plus Saroglitazar $2 \mathrm{mg}$ OD increased HDL level more in group II in comparison with the Atorvastatin plus Fenofibrate group after 24 weeks of therapy. And the advantage of using atorvastatin plus saroglitazar group is that it reduces Total Cholesterol, Serum Triglycerides. LDL, VLDL \& increases HDL more significantly than Group I values to a great extent. But here the cost of using Group II seems to be high for the patients' due to the cost of saroglitazar in comparison with the fenofibrate even though the result obtained by reducing the lipid parameters by given therapy is beneficial to the patients in long term control of lipid profile and thus helps in the overall reduction of morbidity and mortality in patients with type 2 diabetes mellitus with dyslipidemia. We conclude that among 2 groups i.e. those who were administered Group II therapy elicited a clinically meaningful decrease in Sr. Cholesterol, Sr. triglycerides, LDL and VLDL and increased HDL values sustained throughout 24 weeks of treatment in drug-naïve patients of Type $2 \mathrm{DM}$ with Dyslipidemia as compared with Group I.

The results of our study are comparable to the Justification for the Use of Statins in Primary Prevention: An Intervention Trial Evaluating Group I versus Group II. In this Trial provides yet more evidence about the effectiveness of statin therapy in combination with saroglitazar in reducing cardiovascular risk, even among persons who would not currently be considered for pharmacotherapy.

So, we can conclude from the above study that both the groups reduce dyslipidemia in diabetic patients but when reduction in both groups were compared, reduction with Atorvastatin plus Saroglitazar was highly significant but drawback with this group was cost of saroglitazar is more compared to Fenofibrate.

As long-term safety of Fenofibrate is questionable as per FIELD study as it is known to impair renal function, So the combination of Atorvastatin plus Saroglitazar is better option to reduce high Triglycerides level.

\section{REFERENCES}

1. Mohan, V., Sandeep, S., Deepa, R., Shah, B., \& Varghese, C. (2007). Epidemiology of type 2 diabetes: Indian scenario. The Indian journal of medical research, 125(3), 217-30.

2. Shaw, J. E., Sicree, R. A., \& Zimmet, P. Z. (2010). Global estimates of the prevalence of diabetes for 2010 and 2030. Diabetes research and clinical practice, 87(1), 4-14.

3. Anjana, R. M., Pradeepa, R., Deepa, M., Datta, M., Sudha, V., \& Unnikrishnan, R. (2011). ICMRINDIAB Collaborative Study Group. Prevalence of diabetes and prediabetes (impaired fasting glucose and/or impaired glucose tolerance) in urban and rural India: Phase I results of the Indian Council of Medical Research-India Diabetes (ICMR-INDIAB) study. Diabetologia. 54:3022-7.

4. Taskinen, M. R. (1999). Strategies for the management of diabetic dyslipidemia. Drugs. 58:47-51.

5. Turner, R. C., Millns, H., Neil, H. A. W., Stratton, I. M., Manley, S. E., Matthews, D. R., \& Holman, R. R. (1998). Risk factors for coronary artery disease in non-insulin dependent diabetes mellitus: United Kingdom Prospective Diabetes Study (UKPDS: 23). Bmj, 316(7134), 823-828.

6. Farmer, J. A. (2008). Diabetic dyslipidemia and atherosclerosis: evidence from clinical trials. Current Diabetes Reports, 8(1), 71-77.

7. Saydah, S. H., Fradkin, J., \& Cowie, C. C. (2004). Poor control of risk factors for vascular disease among adults with previously diagnosed diabetes. Jama, 291(3), 335-342. 
8. Mukhopadhyay, J., Kanjilal, S., \& Biswas, M. (2010). Diabetic Dyslipidemia: Priorities and Targets in India. Lipids Health Dis, 9, 144. [Last accessed on 2013 Aug 23]; Medicine Update. 2010 20 Available from: http://www.apiindia.org/content_mu_2010.html .

9. O'Keefe Jr, J. H., Miles, J. M., Harris, W. H., Moe, R. M., \& McCallister, B. D. (1999, February). Improving the adverse cardiovascular prognosis of type 2 diabetes. In Mayo Clinic Proceedings (Vol. 74, No. 2, pp. 171-180). Elsevier.

10. UK Prospective Diabetes Study Group. (1998). The incidence of myocardial infarction in white, South Asian, and Afro-Caribbean patients with type 2 diabetes (UK Prospective Diabetes Study 32). Diabetes Care, 21, 1271-1277.

11. Masala, G., Mattiello, A., \& Molina-Montes, E. (2009). American Diabetes Association: Standards of Medical Care in Diabetes-2009. Diabetes Care, 32.

12. Brunzell, J. D., Davidson, M., Furberg, C. D., Goldberg, R. B., Howard, B. V., Stein, J. H., \& Witztum, J. L. (2008). Lipoprotein management in patients with cardiometabolic risk: consensus statement from the American Diabetes Association and the American College of Cardiology Foundation. Diabetes care, 31(4), 811-822.

13. Rosenson, R. S. (2004). Statins: can the new generation make an impression?. Expert opinion on emerging drugs, 9(2), 269-279.

14. Zinman, B., Gerich, J., Buse, J. B., Lewin, A., Schwartz, S., Raskin, P., ... \& Blonde, L. (2010). American Diabetes Association. Standards of medical care in diabetes-2010 (vol 33, pg S11, 2010). Diabetes care, 33(3), 692-692.

15. Moreno, P. R., Murcia, A. M., Palacios, I. F., Leon, M. N., Bernardi, V. H., Fuster, V., \& Fallon, J. T. (2000). Coronary composition and macrophage infiltration in atherectomy specimens from patients with diabetes mellitus. Circulation, 102(18), 21802184.

16. Hurst, R. T., \& Lee, R. W. (2003). Increased incidence of coronary atherosclerosis in type 2 diabetes mellitus: mechanisms and management. Annals of internal medicine, 139(10), 824-834.

17. Kapur, N. K., \& Musunuru, K. (2008). Clinical efficacy and safety of statins in managing cardiovascular risk. Vasc Health Risk Manag. 4;341-353.

18. Jacobson, T. A. (2009). Myopathy with statinfibrate combination therapy: clinical considerations. Nat Rev Endocrinol. 5:507-518.

19. Davidson, M. H., Rooney, M. W., Drucker, J., Griffin, H. E., Oosman, S., \& Beckert, M. (2009). Efficacy and tolerability of atorvastatin/fenofibrate fixed-dose combination tablet compared with atorvastatin and fenofibrate monotherapies in patients with dyslipidemia: A 12-week, multicenter, double-blind, randomized, parallelgroup study. Clinical Therapeutics. 31, 2824-2838.

20. Guerin, M., Lassel, T. S., Le Goff, W., Farnier, M., \& Chapman, M. J. (2000). Action of atorvastatin in combined hyperlipidemia: preferential reduction of cholesteryl ester transfer from HDL to VLDL1 particles. Arteriosclerosis, thrombosis, and vascular biology, 20(1), 189-197.

21. Jones, P., Kafonek, S., Laurora, I., \& Hunninghake, D. (1998). Comparative dose efficacy studyof atorvastatin versus simvastatin, pravastatin,lovastatin, and fluvastatin in patientswith hypercholesterolemia (theCURVES study). Am J Cardiol. 81, 582-587.

22. Dresser, G. K., Spence, J. D., \& Bailey, D. G. (2000). Pharmacokinetic-pharmacodynamic consequences and clinical relevance of cytochrome P450 3A4 inhibition. Clin Pharmacokinet. 38:4157.

23. Christians, U., Jacobson, W., \& Floren, L. C. (1998). Metabolism and drug interactions of 3hydroxy3-methyl gluteryl coenzyme A reductase inhibitors in transplant patients: are mechanistically similar. Pharmacol Ther. 80:1-34.

24. Knowler, W. C., Saad, M. F., Pettitt, D. J, Nelson, R. G., \& Bennett, P. H. (1993). Determinants of diabetes mellitus in the Pima Indians. Diabetes Care. 16(1):216-227.

25. Parikh, R. M., Joshi, S. R., Menon, P. S., \& Shah, N. S. (2010). Prevalence and pattern of diabetic dyslipidemia in Indian type 2 diabetic patients. Diabetes \& Metabolic Syndrome: Clinical Research \& Reviews, 4(1), 10-12.

26. Ii, M., Nishimura, H., Kusano, K. F., Qin, G., Yoon, Y. S., \& Wecker, A. (2005). Neuronal nitric oxide synthase mediates statin-induced restoration of vasa nervorum and reversal of diabetic neuropathy. Circulation. 112:93-102.

27. Elrod, J. W., Lefer, D. J. (2005). The effects of statins on endothelium, inflammation and cardioprotection. Drug News Perspect. 18:229236.

28. Graaf, M. R., Richel, D. J., van Noorden, C. J., \& Guchelaar, H. J. (2004). Effects of statins and farnesyltransferase inhibitors on the development and progression of cancer. Cancer treatment reviews, 30(7), 609-641.

29. Chan, K. A., Andrade, S. E., Boles, M., Buist, D. S., Chase, G. A., Donahue, J. G., ... \& Platt, R. (2000). Inhibitors of hydroxymethylglutarylcoenzyme A reductase and risk of fracture among older women. The Lancet, 355(9222), 2185-2188.

30. Wolozin, B., Kellman, W., Ruosseau, P., Celesia, G. G., \& Siegel, G. (2000). Decreased prevalence of Alzheimer disease associated with 3-hydroxy-3methyglutaryl coenzyme A reductase inhibitors. Archives of neurology, 57(10), 14391443. 
31. Glueck, C. J., Aregawi, D., Agloria, M., Khalil, Q., Winiarska, M., Munjal, J., ... \& Wang, P. (2006). Rosuvastatin 5 and $10 \mathrm{mg} / \mathrm{d}$ : a pilot study of the effects in hypercholesterolemic adults unable to tolerate other statins and reach LDL cholesterol goals with nonstatin lipid-lowering therapies. Clinical therapeutics, 28(6), 933-942.

32. Goudevenos, J. A., Bairaktari, E. T., Chatzidimou, K. G., Milionis, H. J., Mikhailidis, D. P., \& Elisaf, M. S. (2000). The effect of atorvastatin on serum lipids, lipoprotein (a) and plasma fibrinogen levels in primary dyslipidaemia-a pilot study involving serial sampling. Current medical research and opinion, 16(4), 269-275.

33. Stüve, O., Youssef, S., Steinman, L., \& Zamvil, S. S. (2003). Statins as potential therapeutic agents in neuroinflammatory disorders. Current opinion in neurology, 16(3), 393-401.

34. Young-Xu, Y., Chan, K. A., Liao, J. K., Ravid, S., \& Blatt, C. M. (2003). Long-term statin use and psychological well-being. Journal of the American College of Cardiology, 42(4), 690-697.

35. Hunninghake, D. B., Ballantyne, C. M., Maccubbin, D. L., Shah, A. K., Gumbiner, B., \& Mitchel, Y. B. (2003). Comparative effects of simvastatin and atorvastatin in hypercholesterolemic patients with characteristics of metabolic syndrome. Clinical therapeutics, 25(6), 1670-1686.

36. Davidson, M. H. (2002). Rosuvastatin: a highly efficacious statin for the treatment of dyslipidaemia. Expert Opin Investig Drugs. 11(3):125-41.

37. Patel, D. B., Desai, R. N., Anand, I. S., \& Patel, C. N. (2014). Comparative Study of Atorvastatin plus Fenofibrate versus Atorvastatin alone for its safety and efficacy in Hyperlipidemic patients. IJARPB: 4(3):1-7. 